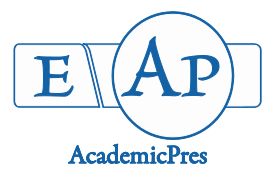

\title{
Molecular Diversity Analysis of Two in vitro and Irradiated Potato Varieties Expressed by Random Amplified Polymorphic DNA
}

\author{
Ayman El-FIKI ${ }^{1 *}$, Zakia ADAM ${ }^{2}$, Thoria MOHAMED ${ }^{2}$, \\ Shimaa SOBIEH ${ }^{2}$, Amal SALAH $^{1}$ \\ ${ }^{1}$ National Centre for Radiation Research and Technology, Nasr City, Cairo, \\ Egypt; aymana.elfiki@eaea.org.eg (*corresponding author); adly4000@yahoo.com \\ ${ }^{2}$ Ain Shams University, Faculty of Women for Arts, Science and Education, Cairo, \\ Egypt; zakiaadam123@gmail.com,thoria.rashad@hotmail.com,ssobieh@yahoo.com
}

\begin{abstract}
Potato buds cvs. Valor' and 'Spunta' were cultured in vitro on MS solid medium with $0.2 \mathrm{mg}^{-1} \mathrm{BAP}$. The resulting plantlets were irradiated with gamma radiation doses 10, 20, 30, 40 and $50 \mathrm{~Gy}$. Irradiated segments were transferred onto fresh MS with BAP and plantlets survival percentage was calculated after eight weeks. Gamma radiation caused the death of $3.8 \%$ to $81 \%$ in cv. 'Spunta' and $2.9 \%$ to $83.9 \%$ in cv. Valor'. Microtubers produced from irradiated plantlets were decreased with increasing gamma radiation doses, with notable changes in shape, size and numbers. The proline contents in irradiated plantlets were steady increase with gamma radiation doses. The genomic DNA of the two cultivars and ten radiation treatments was amplified with 10 RAPD primers that generated 53 polymorphic bands. The highest number of genetic identity was 0.9672 showed between irradiated plantlets with 20 and $30 \mathrm{~Gy}$ in cv. Valor'. However, the highest genetic distance was 0.3995 observed between irradiated plantlets with dose 20 Gy in cv. Valor' and 30 Gy in cv. 'Spunta'. The dendrogram generated by cluster analysis distinguished the irradiated plantlets genetically.
\end{abstract}

Keywords: in vitro, polymorphism DNA, potato, RAPD, radiation

\section{Introduction}

Potato is a crop of worldwide importance and is basic part of the diet of a large proportion of the world's populations (FAO, 2008). The development of efficient in vitro culture methods has facilitated the use of mutation techniques for improvement of both seed and vegetatively propagated crops; mutation induction in combination with in vitro culture techniques may be the effective methods for plant improvement (Novak, 1991). Plant breeders suffer from the lack of availability or existence of required genotypes. Therefore, induced genetic diversity is the basic requirement of plant breeding in developing plant varieties.

Gamma ray is an ionizing radiation where they react with atoms or molecules to produce free radical in cells. Radicals may have harmful effect or act on rearranging the cell components and this effect may appear on the morphology, physiology, biochemistry and anatomy depending on radiation doses. These effects include changes in the plant cellular structure and metabolism, e. g. dilation of thylakoid membranes, alteration in photosynthesis, modulation of the antioxidative system and accumulation of phenolic compounds (Kovacs and Keresztes, 2002; Kim et al., 2004; Wi et al., 2005).

Molecular genetic markers have become useful tools in providing a relatively unbiased estimation of genetic diversity and phylogeny in plants (Clegg, 1990). Over the past decades, PCR techniques have been developed for DNA fingerprinting, each one with specific advantages and disadvantages. Random amplified polymorphic DNA (RAPD) is the simplest and fastest of DNA-based techniques in genetic similarity studies (Gwanama et al., 2002). A number of scientists have used RAPD markers to study polymorphism in various plants (Ortiz et al., 1997; Ranade et al., 2002; Rout and Das, 2002; Samal et al., 2003). In potato, RAPD has been used mainly for the identification and genetic characterization of cultivars (Bered et al., 2005).

The hereby work was an attempt to increase genetic variability in potato (Valor' and 'Spunta') cultivars using gamma radiation as physical mutagen and molecular diversity analysis through RAPD marker. 


\section{Materials and Methods}

\section{Plant material}

Buds from tubers of two commercial tuber seeds (cvs. 'Spunta' and Valor') were excised and surface sterilized by dipping in Clorox (30\%) for ten minutes followed by three rinses in sterile distilled water. The buds were cultured on solid MS medium Murashige and Skoog (1962) without hormone. Micropropagation began after 6-8 weeks when the plantlets were about $10-12 \mathrm{~cm}$ high. The culture was maintained by cutting into single nodes and transferring them onto MS medium supplemented with $0.2 \mathrm{mg}^{-1} \mathrm{BAP}$. The $\mathrm{pH}$ of the culture medium was adjusted to 5.7 before autoclaving and the buds were thereafter incubated in growth chamber at $25^{\circ} \mathrm{C} \pm 2$ under photoperiod $16 \mathrm{~h}$.

\section{Gamma irradiation}

Irradiation was carried out with ${ }^{60} \mathrm{Co}$ source at the dose rate $10 \mathrm{~Gy} / 23 \mathrm{~min} 34 \mathrm{sec}$, at National Centre for Radiation Research and Technology, Cairo, Egypt. Mass cultures of in vitro grown plantlets derived from single nodes were treated with different doses of gamma rays (10, 20, 30, 40, $50 \mathrm{~Gy})$. A further 100 in vitro grown plantlets were irradiated at each dose.

\section{Fresh weight, dry weight and water content}

The fresh weight of the samples was determined directly after taking the samples. Dry weights were determined after drying the samples for 48 and $72 \mathrm{~h}$ at $80{ }^{\circ} \mathrm{C}$. The water content was calculated from the difference between fresh and dry weight.

\section{Acclimatization}

Irradiated plantlets were cultivated in sterile jars containing peat moss and sand with a ratio of $1: 1$. Plastic caps were removed and covered with puncture plastic sheets. After one week the plastic cover sheets were removed and the plantlets were left in growth chamber one week before transfer to the green house.

\section{Tuberization}

The irradiated plantlets were transferred to liquid medium containing half strength MS salt mixture, $8 \%$ sucrose, $2.0 \mathrm{mg}^{-1} \mathrm{BA}$. The $\mathrm{pH}$ of the culture medium was adjusted as above before autoclaving. The cultures were incubated in a growth chamber at $20^{\circ} \mathrm{C}$ under a photoperiod of $8 \mathrm{~h}$ at 400 lux for 3-4 months. The resulting microtubers were cultured in green house for macrotubers. As another way for tuberization, were through acclimatized plantlets cultured on pots containing peat moss and sand 1:1.

\section{Proline content estimation}

The proline content was estimated according to Batels et al. (1973) in irradiated and non- irradiated plantlets.

\section{Genomic DNA isolation}

Total genomic DNA was isolated according to the protocol described by Anderson et al. (1992) in irradiated and non-irradiated potato plantlets cvs. Valor' and 'Spunta'.

\section{RAPD amplification}

Fifteen different primers were chosen arbitrarily. The primers used in the current experiment were 10-mer synthesized by Metabion International AG (Inc. Germany). Primers sequences $\left(5^{\prime}-3^{\prime}\right)$ are as shown in Table 1. Amplification reactions were performed in a $50 \mu \mathrm{l}$ volume, containing: $20 \mathrm{mM}$ Tris-HCl (pH 8.4), $50 \mathrm{mM} \mathrm{KCl}, 2.5$ $\mathrm{mM} \mathrm{MgCl} 2,200 \mu \mathrm{M}$ each of dNTPs, $1 \mu \mathrm{M}$ primer, $30 \mathrm{ng}$ of genomic DNA, 1.5 U of Taq DNA polymerase. The reaction mixture was overlaid with two drops of mineral oil, incubated for $3 \mathrm{~min}$ at $94^{\circ} \mathrm{C}$ for initial denaturation and then amplified for 35 cycles consisting of $1 \mathrm{~min}$ at $94^{\circ} \mathrm{C}, 30 \mathrm{sec}$ at $32.3{ }^{\circ} \mathrm{C}$ and $1.30 \mathrm{~min}$ at $72{ }^{\circ} \mathrm{C}$, followed by $7 \mathrm{~min}$ incubation at $72{ }^{\circ} \mathrm{C}$. Amplification products were separated by gel electrophoresis on $1.0 \%$ agarose and visualized under UV illumination after staining with ethidiam bromide and photographed.

\section{Data analysis}

The size of RAPD fragments were estimated by comparison with the marker. RAPD fingerprints were recorded in the binary form $(1=$ presence of a band and $0=$ absence of a band). All data were scored twice by two independent scorings. A simple matching coefficient was calculated to construct a similarity matrix and the UPGMA algorithm was used to perform hierarchical cluster analysis and to construct a dendrogram by using POPGENE package Version 3.5 (Yeh et al., 1999).

\section{Results and Discussion}

Potato ('Spunta' and 'Valor') cultivars plantlets were exposed to different doses of gamma radiation 10, 20, 30, 40 and 50 Gy. The impact of gamma irradiation caused a decrease in the percent survival of micropropagated buds in both cultivars to $91.4,81.9,68.5,28.5$ and $14.2 \%$ and 93.3 , 87.6, 79 and $30.47 \%$, respectively, as shown in Fig. 1. The shoot lengths of both cultivars in irradiated plantlets were decreasing with increasing gamma radiation doses (Fig. 2). Also, the fresh and dry weights decreased with increased gamma radiation dose in both cultivars (Fig. 3). The resulting microtubers were also decreasing in number and size with increasing gamma radiation doses. The results showed by the radiation sensitivity test based on survival percentage, shoot length and tuberization of irradiated and non-irradiated plantlets, that significant reduction was observed with increasing gamma dosage. Generally, gamma irradiation can be used to obtain varieties that are economically important in agriculture, with high productivity and quality (El-Fiki, 1997; Jain, 2010). They are useful for mutations in breeding programs and in vitro mutagenesis in order to develop required features of plants and increase the genetic variability. Many mutant varieties, which are resistant to biotic and abiotic stress and with high quality, have been developed (Jain et al., 2013). Several attempts of mutagenic treatment on cultured anthers have been reported in higher plants (Sangwan and Sangwan, 1986; MacDonald et al., 1988; Ling et al., 1991; El-Fiki et al., 2015). These results were in accordance with radiation 
sensitivity test done by Hasegawa et al. (1995), El-Fiki et al. $(2015,2016)$ for tobacco, El-Fiki (1997) for potato, El-Fiki et al. (2005a and b) for alfalfa, Norfadzrin et al. (2007) for tomato and okra and Kiong et al. (2008) for Orthosiphon stamineus.

\section{Proline content estimation}

Proline content in irradiated potato plantlets with doses of 10, 20, 30 and $40 \mathrm{~Gy}$ and non-irradiated plants was estimated. Irradiated potato plantlets with gamma radiation doses had a positive impact on proline content in both cultivars. The results showed that the proline content increased with increasing gamma radiation dose (Fig. 4).

The most crucial function of plant cell is to respond to gamma stress by developing defense mechanisms. This defense may be affected by alteration in the pattern of gene expression (Corthals et al., 2000), which may led to

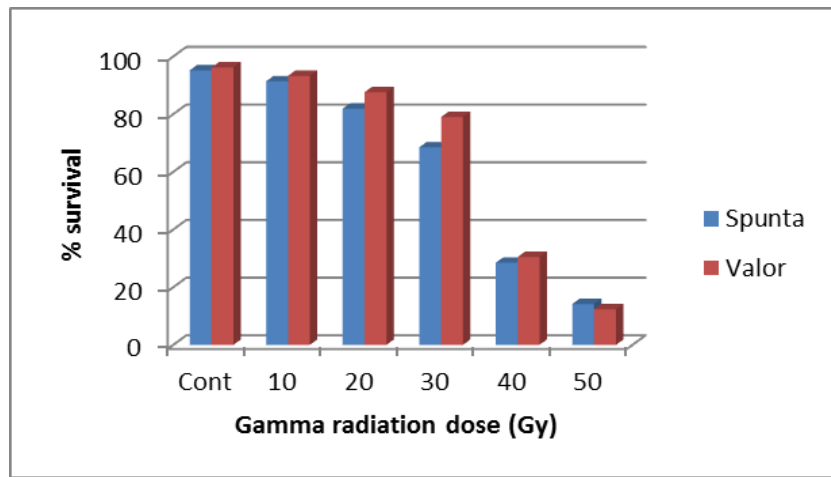

Fig. 1. Gamma radiation impact on potato bud survival percentage cvs. 'Spunta' and 'Valor'

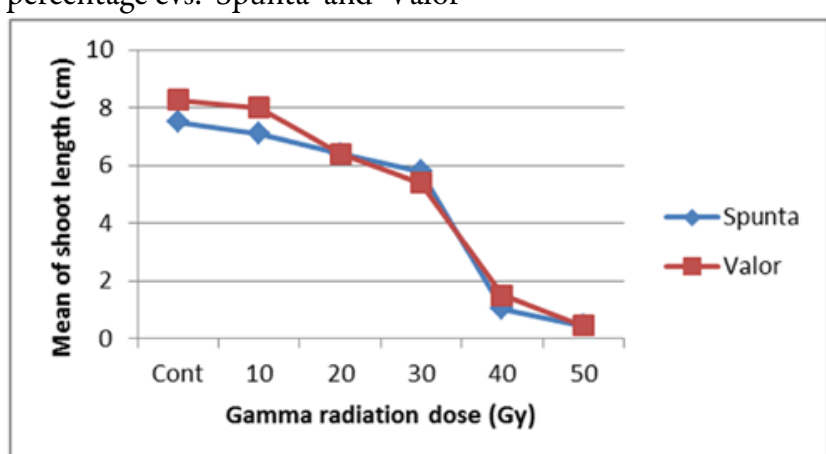

Fig. 2. Gamma radiation impact on potato shoot length cvs. 'Spunta' and 'Valor'

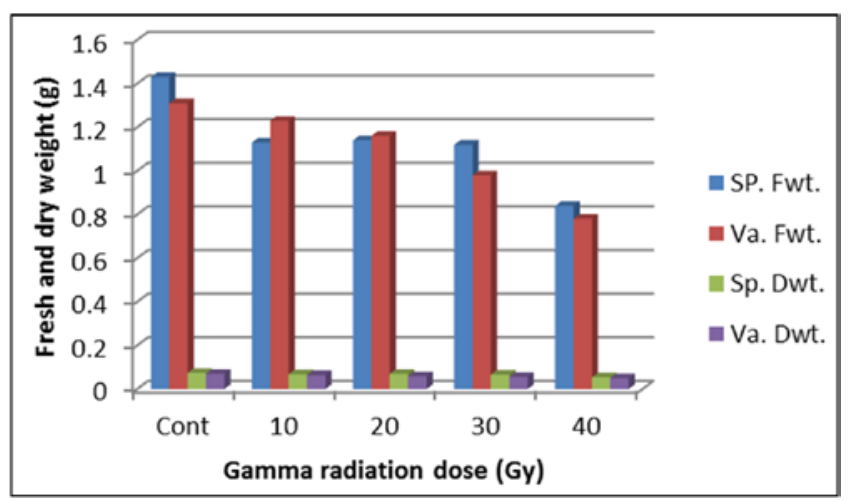

Fig. 3. Gamma radiation impact on potato plantlets fresh and dry weight crs. 'Spunta' and 'Valor' modulation of certain metabolic and defensive pathways (Zolla et al., 2003).

Total genomic DNA from ten radiation treatments of potato cvs. 'Spunta' and 'Valor' were used as templates from RAPD finger printing. Of the 15 RAPD primers tested, 10 primers were selected based on the quality and repeatability of the amplified bands. Altogether, 146 bands were obtained, with an average of 14.6 bands per primer and the band size ranging from $13.061 \mathrm{Kbp}$ to $0.159 \mathrm{Kbp}$ (Table 2). The maximum number of bands was of 13 , produced by primer OP- B07. However, the minimum numbers of bands was 5 , produced by primers OP- B11, OP- L13, OPL16 and OP- Z03. The polymorphic bands ranged from one in primers OP- B11, OP- L12, OP- L20 and OP-Z03, to eight bands in primer OP- B07. The primer OP-B07 produced the maximum number of bands (12) with nonirradiated cv. 'Spunta' and (13) with non-irradiated and irradiated cv.'Valor' by dose 10 Gy. However, the minimum number of bands observed in cvs. 'Spunta' and 'Valor' was 5 bands with primers OP- B11, OP- L16, OP- Z03 and OPL13. These bands have emerged as a result of gamma irradiation with primers OP- B11 (10 Gy), OP- L16 (nonirradiated, 10 and $40 \mathrm{~Gy}$ ) and OP- Z03 (20 and $40 \mathrm{~Gy}$ ) in cv. 'Spunta', while in cv. Valor' these bands were observed with primers OP- L16 and OP- Z03 (non-irradiated, 20, 30 and 40 Gy) and OP- L13 (20 and 30 Gy). All the ten primers were polymorphic. A total of 146 bands were amplified of which 53 (36.3\%) polymorphic across radiation treatments (Table 3 ).

\section{Treatments specific markers}

All ten primers gave specific markers. A total of 37 specific markers were generated. The highest numbers of specific marker was 9 and was from primer OP- B07, while the lowest number of specific marker (1) was obtained from OP- L12 in both cultivars under study. There was a great similarity in the obtained specific markers except primer OP-L12 in both cultivars (Table 4).

\section{Genetic relationships in treatments}

The genetic identity and genetic distance to ten gamma radiation treatments of both potato cultivars Valor' and 'Spunta' are presented in Table 5. The Nei's genetic identity was the highest (0.9672) in treatments pairs 30 and 20Gy in cv. Valor'. However, the lowest genetic identity was $(0.6707)$ in treatments pairs $30 \mathrm{~Gy}$ in cv. 'Spunta' and $20 \mathrm{~Gy}$

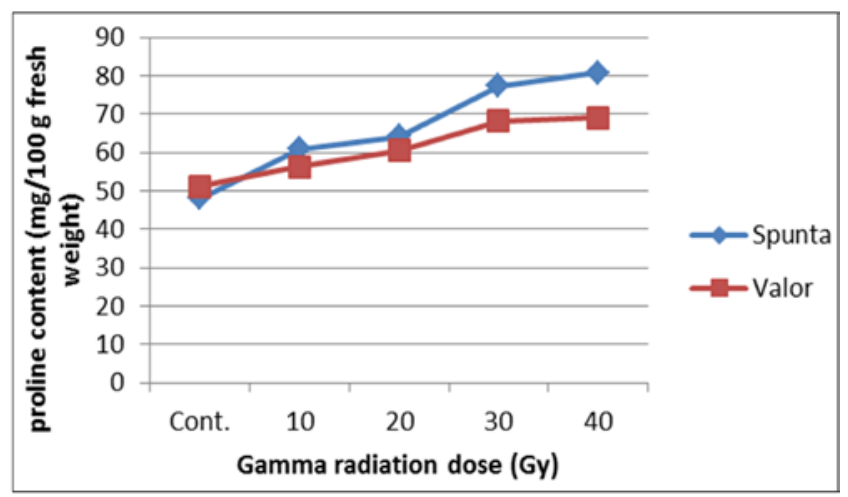

Fig. 4. Gamma radiation impact on proline content in potato plantlets cvs. 'Spunta' and 'Valor' 
48

Table 1. The list of primer's names and their sequences

\begin{tabular}{|c|c|c|c|c|c|}
\hline No & Name & Sequence & No. & Name & Sequence \\
\hline 1 & OP-A02 & TGC CGA GCT G & 9 & OP-C08 & TGG ACC GGT G \\
\hline 2 & OP-A12 & TCG GCG ATA G & 10 & OP-F06 & AGG TGC GTC C \\
\hline 3 & OP-B-01 & CTG TCG TCG T & 11 & OP-L12 & GGG CGG TAC T \\
\hline 4 & OP-B07 & AGG TGA CCG T & 12 & OP-L13 & ACC GCC TGC T \\
\hline 5 & OP-B10 & CTG CTG GGAC & 13 & OP-L16 & AGG TTG CAG G \\
\hline 6 & OP-B11 & CAG CAC TGC T & 14 & OP-L20 & TGG TGG ACC A \\
\hline 7 & OP-B12 & CCT TGA CGC A & 15 & OP-Z03 & CAG CAC CCC A \\
\hline 8 & OP-C02 & GTG AGG CGTC & & & \\
\hline
\end{tabular}

Table 2. Sequence of primers tested, the numbers of DNA fragments amplified and the size a kilobases (Kbp) in potato cvs. 'Valor' and 'Spunta'

\begin{tabular}{|c|c|c|c|c|c|}
\hline \multirow[b]{2}{*}{ Primer No. } & \multirow[b]{2}{*}{ Sequence } & \multicolumn{2}{|c|}{ 'Valor' } & \multicolumn{2}{|c|}{ 'Spunta' } \\
\hline & & $\begin{array}{l}\text { No. of } \\
\text { bands }\end{array}$ & Band size range/kbp & $\begin{array}{l}\text { No. of } \\
\text { bands }\end{array}$ & Band size range/kbp \\
\hline OP-B01 & CTG TCG TCG T & 9 & $1.399-0.218$ & 8 & $1.399-0.218$ \\
\hline OP-B07 & AGG TGA CCG T & 13 & $1.568-0.189$ & 12 & $1.568-0.189$ \\
\hline OP-B11 & CAG CAC TGC T & 7 & $0.863-0.220$ & 5 & $0.863-0.220$ \\
\hline OP-B12 & CCT TGA CGC A & 9 & $2.655-0.177$ & 8 & $1.874-0.177$ \\
\hline OP-F06 & AGG TGC GTC C & 9 & $13.061-0.187$ & 7 & $1.491-0.187$ \\
\hline OP-L12 & GGG CGG TAC T & 8 & $0.193,0.274$ & 7 & $0.193,0.274$ \\
\hline OP-L13 & ACC GCC TGC T & 5 & $0.841-0.294$ & 7 & $1.699,0.255$ \\
\hline OP-L16 & AGG TTG CAGG & 5 & $0.328,0.144$ & 5 & $0.328,0.144$ \\
\hline OP-L20 & TGG TGG ACC A & 6 & $0.835,0.221$ & 6 & $0.835,0.221$ \\
\hline OP-Z03 & CAG CAC CCC A & 5 & $0.391,0.159$ & 5 & $0.391,0.159$ \\
\hline Total & & 76 & & 70 & \\
\hline
\end{tabular}

Table 3. Number and percentage of polymorphic loci obtained in 10 potato gamma radiation treatments on cvs. 'Valor' and 'Spunta'

\begin{tabular}{|c|c|c|c|c|c|c|c|c|}
\hline \multirow{3}{*}{$\begin{array}{c}\text { Primer } \\
\text { No. }\end{array}$} & \multicolumn{4}{|c|}{ 'Valor' } & \multicolumn{4}{|c|}{ 'Spunta' } \\
\hline & \multicolumn{4}{|c|}{ Gel polymorphism } & \multicolumn{4}{|c|}{ Gel polymorphism } \\
\hline & $\begin{array}{c}\text { Total band } \\
\text { no. }\end{array}$ & $\begin{array}{c}\text { Monomorphic } \\
\text { bands }\end{array}$ & $\begin{array}{c}\text { Polymorphic } \\
\text { bands }\end{array}$ & $\begin{array}{c}\text { Polymorphism } \\
(\%)\end{array}$ & $\begin{array}{c}\text { Total } \\
\text { band no. }\end{array}$ & $\begin{array}{c}\text { Monomorphic } \\
\text { bands }\end{array}$ & $\begin{array}{c}\text { Polymorphic } \\
\text { bands }\end{array}$ & $\begin{array}{c}\text { Polymorphism } \\
(\%)\end{array}$ \\
\hline $\begin{array}{l}\text { OP- } \\
\text { B01 }\end{array}$ & 9 & 6 & 3 & $33.33 \%$ & 8 & 5 & 1 & $37.5 \%$ \\
\hline $\begin{array}{l}\text { OP- } \\
\text { B07 }\end{array}$ & 13 & 11 & 2 & $15.83 \%$ & 12 & 4 & 3 & $66.66 \%$ \\
\hline $\begin{array}{l}\text { OP- } \\
\text { B11 }\end{array}$ & 7 & 4 & 0 & $42.85 \%$ & 5 & 4 & 0 & $20.00 \%$ \\
\hline $\begin{array}{l}\text { OP- } \\
\text { B12 }\end{array}$ & 9 & 6 & 2 & $33.33 \%$ & 8 & 6 & 1 & $25.00 \%$ \\
\hline $\begin{array}{l}\text { OP- } \\
\text { F06 }\end{array}$ & 9 & 4 & 4 & $55.55 \%$ & 7 & 2 & 3 & $71.42 \%$ \\
\hline $\begin{array}{l}\text { OP- } \\
\mathrm{L} 12\end{array}$ & 8 & 7 & 0 & $12.50 \%$ & 7 & 6 & 1 & $14.28 \%$ \\
\hline $\begin{array}{l}\mathrm{OP}- \\
\mathrm{L} 13\end{array}$ & 5 & 3 & 2 & $40.00 \%$ & 7 & 3 & 2 & $57.14 \%$ \\
\hline $\begin{array}{l}\text { OP- } \\
\mathrm{L} 16\end{array}$ & 5 & 3 & 2 & $40.00 \%$ & 5 & 3 & 2 & $40.00 \%$ \\
\hline $\begin{array}{l}\text { OP- } \\
\text { L20 }\end{array}$ & 6 & 5 & 1 & $16.66 \%$ & 6 & 4 & 1 & $33.33 \%$ \\
\hline $\begin{array}{l}\text { OP- } \\
\mathrm{Z} 03\end{array}$ & 5 & 4 & 1 & $20.00 \%$ & 5 & 3 & 2 & $40.00 \%$ \\
\hline Total & 76 & 53 & 17 & $30.26 \%$ & 70 & 40 & 16 & $42.85 \%$ \\
\hline
\end{tabular}


in cv. Valor'. On the other hand, the highest Nei's genetic distance was (0.3995) between the two treatments $20 \mathrm{~Gy}$ in cv. Valor' and 30 Gy in cv. 'Spunta'. Whereas, the lowest Nei's genetic distance was $(0.0333)$ within irradiated Valor' with dose 20 Gy.

\section{RAPD based genetic relationships}

A dendrogram based on Nei's (1972) genetic distance using unmeasured pair group method of arithmetic mean (UPGMA) was established with 10 gamma irradiation treatments in potato cvs. Valor' and 'Spunta' (Fig. 5). These treatments segregated into two main clusters. The first cluster contained non-irradiated Valor' and 'Spunta' with gamma irradiation doses 10, 20, 30 and 40Gy to cv. Valor'. The second cluster includes other gamma radiation doses 10, 20, 30 and 40Gy of cv. 'Spunta'. The highest genetic distance level was (6.14499) observed between group 6 and dose 40 Gy in cv. Valor'. However, the lowest genetic distance level was (1.52699) showed between group 4 and 2 .

Molecular markers have become an effective tool by which both intra- and inter-species genetic diversity can be evaluated and characterized. Marker systems are distinguished by the extent (i.e., magnitude) of their informativeness, which in turn depends on the degree of polymorphism. The concept of polymorphism is used to determine the genetic variability in a population, which in recent decades has become the subject of intense study by various disciplines (genetics, ecology, botany, zoology and others). Examples of this are numerous and obvious (Chesnokov and Artemyeva, 2015). The development of PCR techniques and random primers led to amplify a set of randomly distributed loci in any genome facilitating the development of genetic markers for a variety of purposes (Williams et al., 1990; Welsh and McClelland, 1994). The simplicity and applicability of the RAPD technique have captivated many scientists' interests. The main reason for the success of the RAPD analysis is that one can obtain a large number of genetic markers that require small amounts of DNA without the requirement for cloning, sequencing or any other form of the molecular characterization of the genome. Although the RAPD method is relatively fast, cheap and easy to perform in comparison with other methods that have been used as DNA markers, the issue of reproducibility has been of much concern since the publication of the technique. The PCR is very sensitive to any changes that may occur in the reaction conditions, but the RAPD reaction is far more sensitive than conventional PCR because of the length of a single and arbitrary primer used to amplify anonymous regions of a given genome. This reproducibility problem is usually the case for bands with lower intensity. The reason for bands with high or lower intensity is still not known. Perhaps some primers do not perfectly match the priming sequence, amplification in some cycles might not occur, and therefore bands remain fainter. The chance of these kind of bands being sensitive to reaction conditions of course would be higher than those with higher intensity amplified with primers perfectly matching the priming sites. The most important factor for reproducibility of the RAPD profile has been found to be the result of inadequately prepared template DNA (Welsh and McClelland, 1994). Differences between the template DNA concentration of 2 individuals DNA samples result in the loss or gain of some bands (Bardakci, 1996). The cultivars identification using RAPD markers is well-

Table 4. Used primers and the specific RAPD markers generated for gamma radiation treatments

\begin{tabular}{ccc}
\hline & \multicolumn{1}{c}{ 'Valor' } & \multicolumn{1}{c}{ Spunta' } \\
\hline Primer No. & Specific band marker $(\mathrm{bp})$ & $1.399,0.852,0.684$ \\
\hline OP-B01 & $1.399,0.852,0.684$ & $1.568,1.272,1.050,0.870,0.626,0.455,0.372,0.189$ \\
OP-B07 & $1.568,0.220$ & 0.410 \\
OP-B11 & $0.410,0.346,0.289$ & $1.874,0.177$ \\
OP-B12 & $2.655,1.874,1.109,0.177$ & $1.491,0.959,0.637,0.427,0.352$ \\
OP-F06 & $13.061,1.491,0.959,0.637,0.352$ & 1.211 \\
OP-L12 & 10.703 & $1.699,0.841,0.294,0.255$ \\
OP-L13 & $0.841,0.294$ & $0.430,0.328$ \\
OP-L16 & $0.430,0.328$ & $0.835,0.610$ \\
OP-L20 & 0.835 & $0.591,0.391$ \\
OP-Z03 & 0.591 & \\
\hline
\end{tabular}

Table 5. Genetic identity (above diagonal) and genetic distance (below diagonal) values among of 10 gamma radiation treatments in potato cvs. 'Valor' and 'Spunta'

\begin{tabular}{|c|c|c|c|c|c|c|c|c|c|c|}
\hline ID & 1 & 2 & 3 & 4 & 5 & 6 & 7 & 8 & 9 & 10 \\
\hline 1 & **** & 0.8800 & 0.8559 & 0.8559 & 0.8757 & 0.9167 & 0.7740 & 0.7986 & 0.7235 & 0.8389 \\
\hline 2 & 0.1278 & **** & 0.7163 & 0.7650 & 0.7540 & 0.8984 & 0.8311 & 0.7461 & 0.8408 & 0.7542 \\
\hline 3 & 0.1556 & 0.3336 & **** & 0.9672 & 0.9006 & 0.8244 & 0.7067 & 0.7671 & 0.6707 & 0.8721 \\
\hline 4 & 0.1556 & 0.2678 & 0.0333 & $* * * *$ & 0.8684 & 0.8389 & 0.7219 & 0.7671 & 0.7206 & 0.8209 \\
\hline 5 & 0.1327 & 0.2824 & 0.1047 & 0.1411 & $* * * *$ & 0.8610 & 0.7912 & 0.7842 & 0.6985 & 0.8729 \\
\hline 6 & 0.0869 & 0.1071 & 0.1931 & 0.1757 & 0.1496 & **** & 0.8463 & 0.8542 & 0.7720 & 0.8346 \\
\hline 7 & 0.2562 & 0.1850 & 0.3472 & 0.3259 & 0.2341 & 0.1669 & $* * * *$ & 0.8820 & 0.8877 & 0.8780 \\
\hline 8 & 0.2249 & 0.2929 & 0.2652 & 0.2652 & 0.2431 & 0.1576 & 0.1256 & $* * * *$ & 0.8034 & 0.8936 \\
\hline 9 & 0.3237 & 0.1734 & 0.3995 & 0.3277 & 0.3587 & 0.2588 & 0.1191 & 0.2189 & $* * * *$ & 0.7795 \\
\hline 10 & 0.1757 & 0.2821 & 0.1369 & 0.1974 & 0.1360 & 0.1809 & 0.1301 & 0.1125 & 0.2491 & $* * * *$ \\
\hline
\end{tabular}




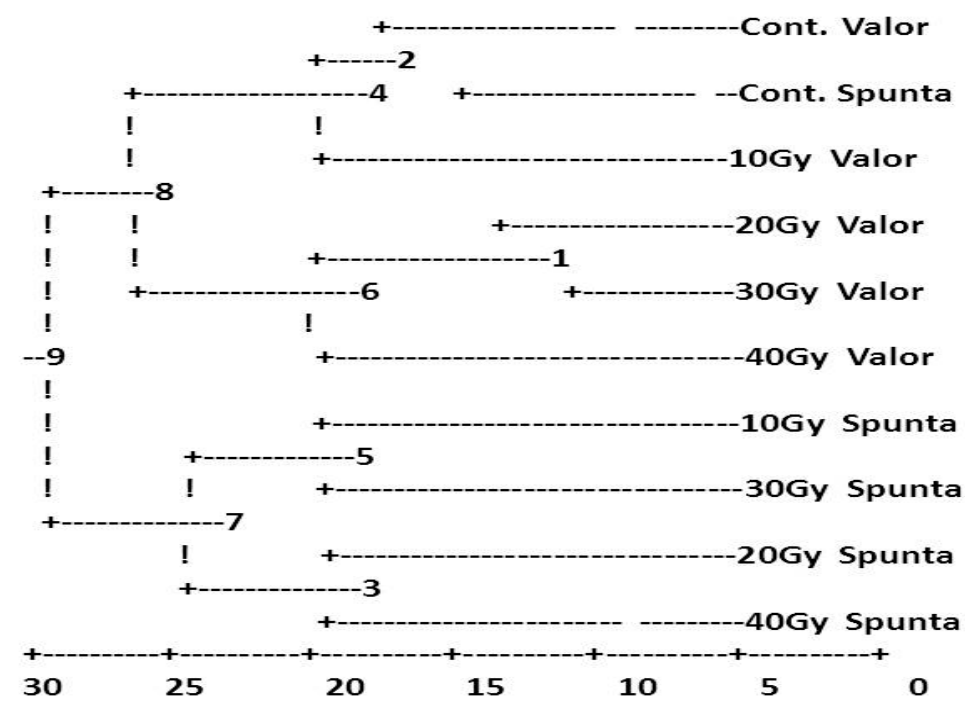

Fig. 5. Dendrogram of ten gamma radiation doses treatment of potato cvs. 'Valor' and 'Spunta'

documented in studies of molecular characterization (Bianchi et al., 2003; Crochemore et al., 2004). Fingerprinting based on this marker type was used for identification and characterization of potato cultivars in North America (Sosinski and Douches, 1996), Australia (Ford and Taylor, 1997) and India (Chakrabarti et al., 1998). Molecular genetic markers have become useful tools in providing a relatively unbiased estimation of genetic diversity and phylogeny in plants (Clegg, 1990). Several different PCR techniques for DNA fingerprinting have been developed during the last decades, each one with specific advantages and disadvantages. Random amplified polymorphic DNA (RAPD) is the simplest and fastest of DNA-based techniques in genetic similarity studies (Gwanama et al., 2002). A number of scientists have used RAPD markers to study polymorphism in various plants (Ortiz et al., 1997; Ranade et al., 2002; Rout and Das, 2002; Samal et al., 2003).

\section{Conclusions}

The use of gamma radiation as a tool for inducing genetic variations in plants represents an efficient method. Gamma irradiation had a negative impact on growth rate, number and microtubers size of potato plantlets. In addition, the use of RAPD as a genetic marker remains the fastest, easiest, cheapest and effective way to differentiate between varieties and treatments.

\section{Acknowledgements}

The research work was supported by grants from National Centre for Radiation Research and Technology, Egyptian Atomic Energy Authority.

\section{References}

Anderson JA, Ogihara Y, Sorrells ME, Tanksley SD (1992). Development of a chromosomal arm map for wheat based on RFPL markers. Theoretical and Applied Genetics 83(8):1035-1043.
Bardakci F (1996). Applications of the random amplified polymorphic DNA (RAPD) technique in tilapia: species, subspecies and sex identification. PhD Thesis, University of Wales Swansea.

Batles LS, Waldern RP, Teare ID (1973). Rapid determination of free praline for water stress studies. Plant and Soil 39:205.

Beetham PR, Kipp PB, Sawycky XI, Arntzen CJ, May GD (1999). A tool for functional plant genomics: chimeric RNA/DNA oligonucleotides cause in vivo gene-specific mutations. Proceedings of the National Academy of Sciences USA 96(15):9774-8778.

Bered F, Terra TF, Spellmeier M, Neto JFB (2005). Genetic variation among and within sweet corn populations detected by RAPD and SSR markers. Crop Breeding and Applied Biotechnology 5(4):418-425.

Bianchi VJ, Fachinello JC, Schuch MW (2003). RAPDs on genetic molecular characterization and genetic variability study of plums. Revista Brasileirade Fruticultura 25(2):272-274.

Chakrabarti SK, Birhman RK, Pattanayak D (1998). Genetic similarity analysis and identification of Indian potato cultivars by random amplified polymorphic DNAs. Indian Journal of Experimental Biology 37:1123-1128.

Clegg MT (1990). Molecular diversity in plant populations, in plant population genetics, breeding and genetic resources. In: Brown AHD, Clegg MT, Kahler AL, Weir BS (Eds). Plant population genetics, breeding, and genetic resources. Sinauer Association Inc.

Corthals G, Gygi S, Aebersold R, Patterson SD (2000). Identification of proteins by mass spectrometry. Proteome Research 21(1):197-231.

Crochemore ML, Nunes LM, Andrade A, Molinari HBCM, Vasconcellos ME (2004). Varietal identification of coffee seed by RAPD technique. Brazilian Archives of Biology and Technology 47(1):7-11.

El-Fiki A, El-Metabteb G, Sayed A, Adly M (2015). Androgenesis induced in Nicotiana alata and the effect of gamma irradiation. Notulae Scientia Biologicae 7(1):66-71.

El-Fiki A, Sayed A, El-Metabteb G, Adly M (2016). Gamma irradiation induced genetic diversity in haploid Nicotiana alata and selection of salt tolerance and detection these differences by RAPD. Notulae Scientia Biologicae 8(1):73-80. 
El-Fiki A, Sayed AIH, Abdel-Hameed AAM (2005a). The combined effect of gamma radiation and mannitol on callus formation and regeneration in alfalfa (Medicago sativa L.). International Journal of Agriculture \& Biology 7(6):966-972

El-Fiki A, Sayed AIH, Abdel-Hameed AAM (2005b). Genotype, explant, medium, light and radiation effects on the in vitro plant regeneration in alfalfa (Medicago sativa L.). Isotope and Radiation Research 37(2):437453.

El-Fiki AAM (1997). Induction of genetic variability by using gamma radiation and selection for salt tolerance in vitro in potato (Solanum tuberosum). Journal of Genetics \& Breeding 51:309-312.

FAO (2008). Land and plant nutrition management service. Retrieved 25 April 2008 from http://www.fao.org/ag/ag//agll/spush/.

Ford R, Taylor PWJ (1997). The application of RAPD markers for potato cultivar identification. Australian Journal Agriculture Research 48:12131217.

Fox MS (1998). Some recollections and reflections on mutation rates. Genetics 148:1415-1418.

Gwanama C, Labuschagne MT, Botha AM (2002). Analysis of genetic variation in Cucurbita moschata by random amplified polymorphic DNA(RAPD) markers. Euphytica 113:19-24.

Hasegawa H, Takashima S, Nakamura A (1995). Effect of gamma ray irradiation on cultured anthers of tobacco (Nicotiana tabacum L.) radiosensitivity and morphological variants appearing in the haploid plants. Plant Tissue Culture Letters 12(3):281-287.

Haberlandt G (1913).Zur Physiologie der Zellteilung. Sitz Kgl Preuss Akad Wiss (Berlin) 16:318-345.

Haberlandt G (1922). Uber Zellteilungs-Hormone und ihre Beziehungen zur Wundheilung und Befruchtung Parthenogenesis und Adventivembryonie. Bio Zentralbl 42:145-172.

Jain SM (2010). Mutagenesis in crops improvement under the climate change. Romanian Biotechnological Letters 15:88-106.

Jain SM, BrarDS, Ahloowalia BS (2013). Somaclonal variation and induced mutations in crop improvement. Springer Science \& Business Media.

Kim JH, Baek MH, Chung BY, Wi SG, Kim JS (2004). Alterations in the photosynthic pigments and antioxidant machineries of red pepper (Capsicum annum $\mathrm{L}$.) seedlings from gamma irradiated seeds. Journal of Plant Biology 47(4):314321.

Kiong ALP, Lai AG, Hussein S, Harun A (2008). Physiological responses of Orthosiphon stamineus plantlets to gamma irradiation. AmericanEurasian Journal of Sustainable Agriculture 2(2):135-149.

Kovacs E, Keresztes A (2002). Effect of gamma and UV-B/C radiation on plant cell. Micron 33(4):199-210.

Ling DX, Luckett DJ, Darvey NL (1991). Low-dose gamma irradiation promotes wheat anther culture response. Australian Journal of Botany 39(5): $467-474$.
MacDonald MV, Hadwieger MA, Aslam FN, Ingram DS (1988). The enhancement of anther culture efficiency in Brassica napus ssp. oleifera Metzg. (Sinsk.) using low doses of gamma irradiation. New Phytologist 110:101-107.

Murashige T, Skoog F (1962). A revised medium for rapid growth and bio assay with tobacco tissue cultures. Physiologia Plantarum 15(3):473497.

Nei M (1972). Genetic distance between populations. American Naturalist 106:283-292.

Norfadzrin F, Ahmed OH, Shaharudin S, Abdul Rahman D (2007). A preliminary study on gamma radiosensitivity of tomato and okra. International Journal of Agricultural Research 2(7):620-625.

Novak FJ (1991). In vitro mutation system for crop improvement. In: Plant Mutation Breeding for Crop Improvement, Vol 2 , IAEA, Vienna pp 327-342.

Ortiz A, Renaud R, Calzada I, Ritter R (1997). Analysis of plum cultivars with RAPD markers. Journal of Horticultural Science 72(1):1-9.

PredieriS (2001). Mutation induction and tissue culture in improving fruits. Plant Cell, Tissue and Organ Culture 64:185-219.

Randade SA, Verma A, Gupta M, Kumar N (2002). RAPD profile analysis of betel vine cultivars. Biologia Plantarum 45:523-527.

Rout GR, Das G (2002). An assessment of genetic integrity of micropropagated plants of Plumbago zeylanica by RAPD markers. Biologia Plantarum 45:27-32.

Samal S, Rout GR, Nayak S, Nanda RM, Lenka PC, Das P (2003). Primer screening and optimization for RAPD analysis of cashew. Biologia Plantarum 46:301-304.

Sangwan RS, Sangwan BS (1986). In: Nuclear techniques and in vitro cultured plant tissues. Austria, Vienna, IAEA pp 181-185.

Sosinski B, Douches DS (1996). Using polymerase chain reaction-based DNA amplification to fingerprint North American potato cultivars. HortScience 31(1):130-133.

Welsh J, McClelland M (1990). Fingerprint genomes using PCR with arbitrary primers. Nucleic Acids Research 18(24):7213-7218.

WiSG, Chung BY, Kim JH, BaekMH, YangDH,LeeJW, Kim JS (2005). Ultrastructural changes of cell organelles in Arabidopsis stem after gammairradiation. Journal of Plant Biology 48(2):195-200.

Yeh FC, Yang RC, Boyle TBJ, Ye ZH, Mao JX (1999). POPGENE. The user friendly software for population genetic analysis.

Zhu TD, Peterson DJ, Tagiiani L, Clair GSt, Baszczynski CL, Bowen B (1999). Targeted manipulation of maize genes in vivo using chimeric RNA/DNA oligonucleotides. Proceedings of the National Academy ofSciences USA 96(15):8768-8773.

Zolla L, Timperio AM, Walcher W, Huber CG (2003). Proteomics of light harvesting proteins in different plant species. Plant Physiology 131(2):198-214. 